1932 Upper Air Current in the Typhoon (Second Paper). Journ. Meteor. Soc. Japan, 10 (12) 679-685 (in Japanese).

Riehl, H.:

1950 A Model of Hurricane Formation. App. Phys. 21 (9) 917-925.

Sawyer, J. S.:

1947 Notes on the Theory of Tropical Cyclones. Quart. J. Roy. Meteor. Soc. 73, 101-126. Syōno, S.:

1948 On the Dynamics of Amalgamation of Cyclones. Geophys. Notes, Tokyo Univ. 1 (7).

1949 Approximate Solution of Non-linear Differential Equation of Stationary Wind in Axialsymmetric Oyclone and Anticyclone and its Applications. (in Japanese) Jour. Meteor. Soc. Jap. 22, 365-391, Geophys. Mag. 20, 39-65 (English translation).

1950 On the Vortical Rain. Geophys. Notes, Tokyo Univ. 3 (25)

1951 On the Structure of Atmospheric Vortices. J. Meteor. 8, 103-110.

\title{
On the Secular Change of the North Pacific High
}

\section{Takeo Yamamoto}

\author{
(Yamaguchi University)
}

We have the continual observation records of the amount of precipitation and the number of rainy days in Seoul during the period of about 200 years previous to the establishment of meteorological observations by the Japanese in 1908. The data, quite valuable, were discovered by the late Dr. Y. Wada and were published as the "Report of the Investigations on the Observation Data in the Historical Age in Korea ".(1) Recently Mr. T. Taguchi(2) has investigated the diary of the Ishikawa family in Minami-tama District, Tokyo Metropolis, which has been written continuously since 1720 up to the present. In Fig. 1, the 10-year moving means of the number of clear days in the summer season (June-Aug.) noted in the "Ishikawa-diary" are shown, compared with those of the amount of summer precipitation (June-Aug.) in Seoul. We can find a close agreement of the curve of clear days in Tokyo (B) with the curve of precipitation in Seoul (A), allowing the phase lag of 10 and odd years. As shown in Fig. 2, the amount of summer precipitation in Seoul is correlated with the temperature difference between $Z$ yoshin or Songchin $\left(40^{\circ} 40^{\prime} \mathrm{N}\right.$, $\left.129^{\circ} 11^{\prime} \mathrm{E}\right)$ and Zinsen or Inchon $\left(37^{\circ} 29^{\prime} \mathrm{N}, 126^{\circ} 38^{\prime} \mathrm{E}\right)$, the correlation coefficient being $B=$ +0.4 (1905-1944). The convergence of the two general air currents, one of which is revolving around the North Pacific High and the other around the Continental Low, tends to form a frontal zone along the middle line of the Korean Peninsula from north to south. With the increase of the intensity of North Pacific High, its western margin bulges out towards the eastern side of the Korean Peninsula, and raises the air temperature there to 

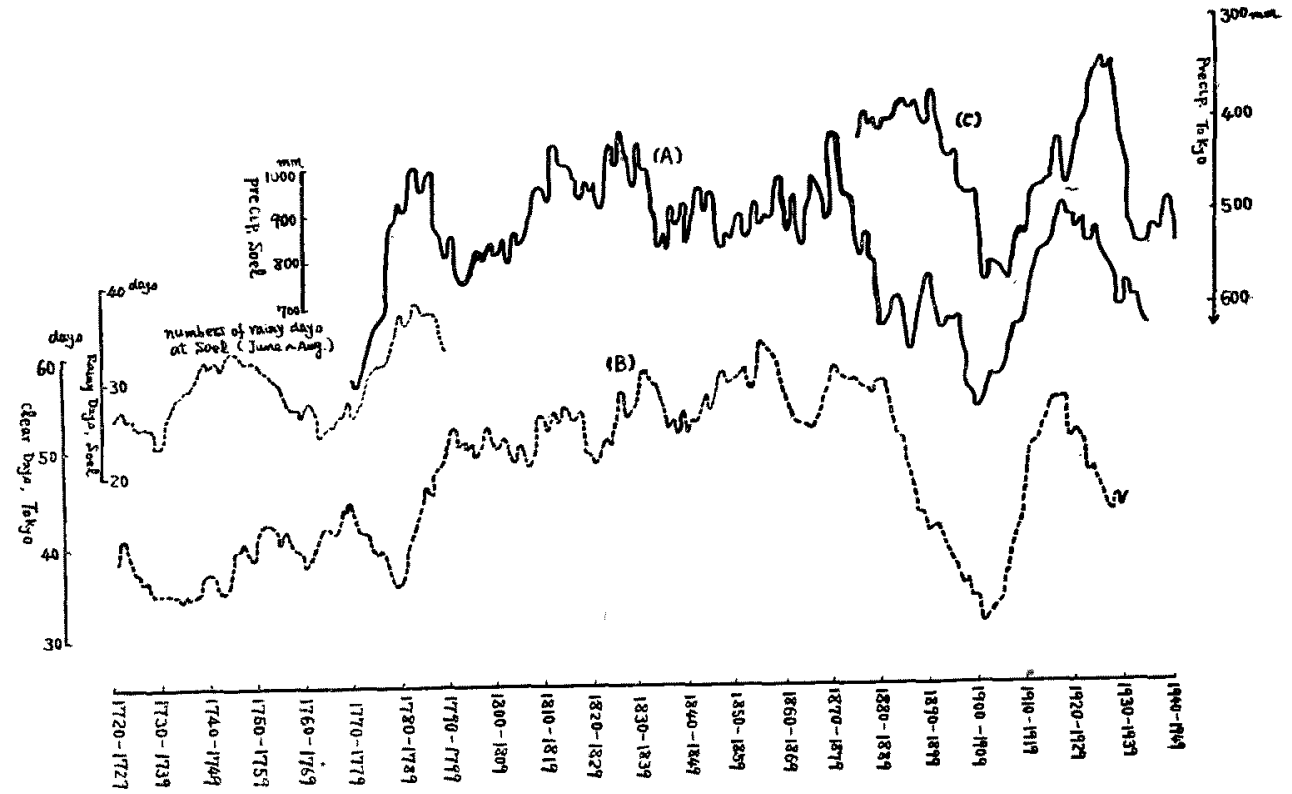

Fig. 1 Secular change of the rainfalls in the Far East

(A) 10-year running means of the amount of precipitation an Seoul in Korea. (June-Aug.)

(B) " " of the numbersor clear days at Tokyo in Japan ( " )

(C) " " of the amount of precipitation at Tokyo in Japan( , ).

the values comparatively higher than on the western side. With the projection of the North Pacific High, the frontal zone shifts towards the western side of the Korean Peninsu la, causing the increase of the amount of summer precipitation in Seoul and the decrease of rainfall in the middle and northern parts of Japan, where the stable maritime air-mass is predominant. ${ }^{(3)}$

When the intensity of the North Pacific High increases over a certain extent, however, it may cause the

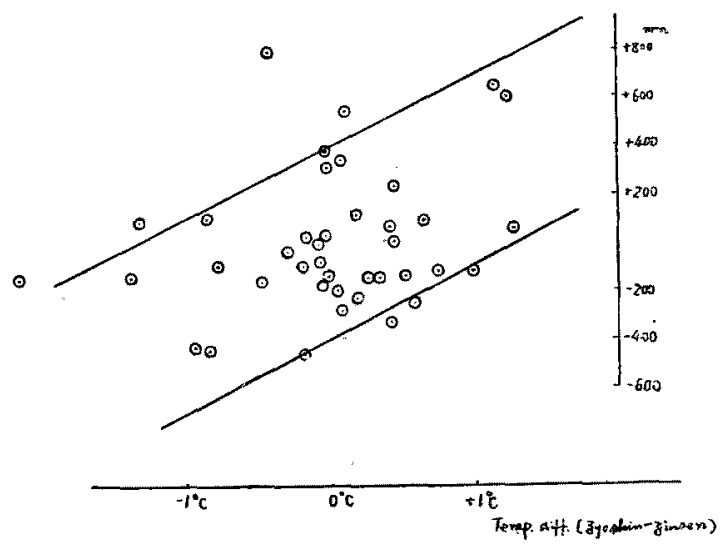

Fig. 2 Contemporary correlation of amount of precip. (June-Aug.) at Seoul with the temp. diff. between Zyoshin and Zinsen

lowering of the amount of summer precipitation in Seoul, shifting the frontal zone towards: the western side of the Peninsula, and it may cause the decrease in the number of clear days in Tokyo, increasing the instability of the tropical maritime air-mass in Kanto District, due to higher air temperatures on the earth's surface produced by larger transport of: 

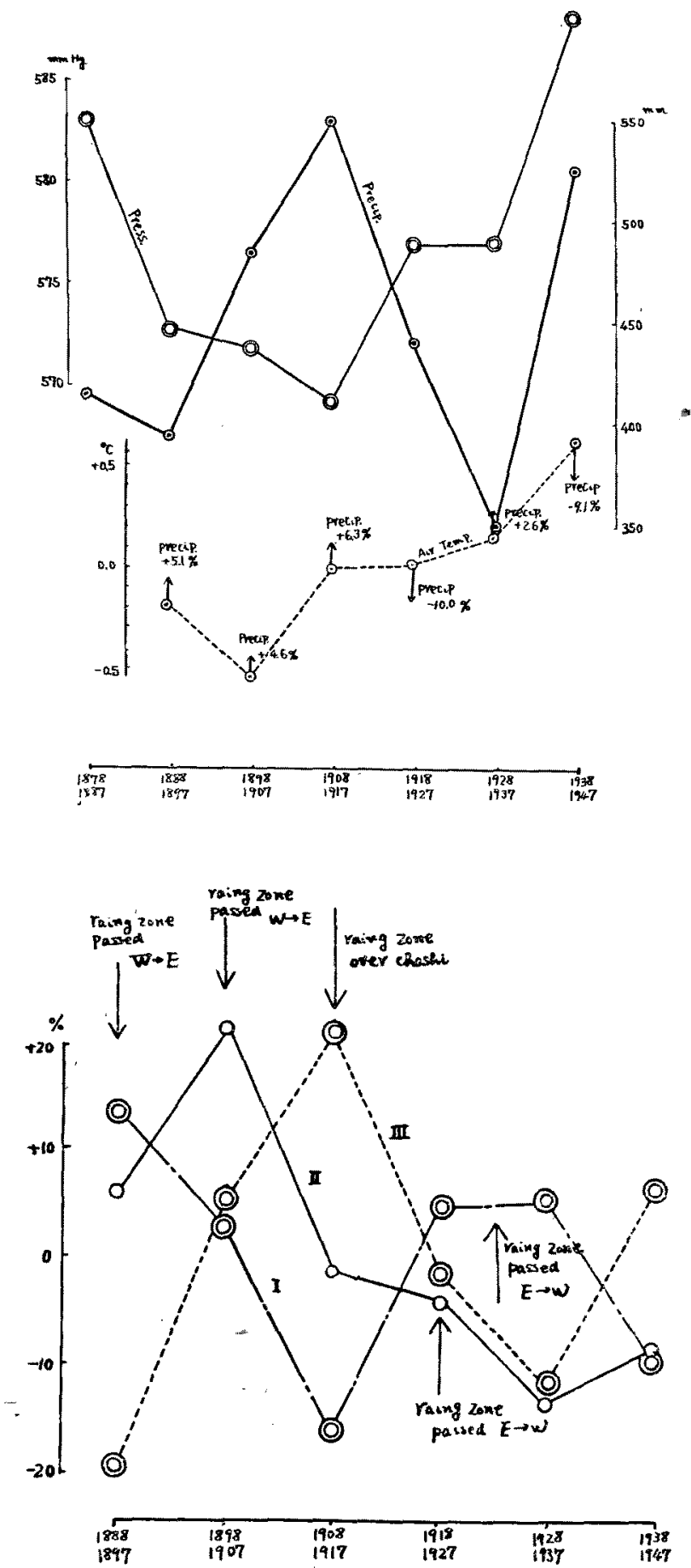

Fig. 3 Secular change of summer pressure (June-Aug.) amount of summer precipitations at $\mathrm{To}$ kyo, and summer air temp. at Nagano

Fig. 4 Secular change of the amount of summer precip. (June-Aug.) in Japan

I Sakai $133^{\circ} 14^{\prime} \mathrm{E} \quad 35^{\circ} 53^{\prime} \mathrm{N}$

II Gifu $136^{\circ} 46^{\prime} \mathrm{E} \quad 35^{\circ} 24^{\prime} \mathrm{N}$

III. Choshi $140^{\circ} 52^{\prime} \mathrm{E} 35^{\circ} 44^{\prime} \mathrm{N}$. 
heat from lower latitudes. In Fig. 3, it will be seen that the amount of summer precipitation at Tokyo is increasing from the 1928-1937 period to the $1938-1947$ period, parallel to the pressure in Tokyo and the rising of air temperature at Nagano, where the variation of the amount of precipitation which may have some effects npon air temperature is very small. As shown in Fig. 4, the rainy zone moves eastwards from the 1888-1897 period to the 1908-1917 period and then westwards through the Japanese mainland.(4) The curves of precipitation in Seoul as well as of clear days in Tokyo (Fig. 1, A and B) have period of rapid increase in precipitation of about 90 years from the end of the 18 th century to the end of the 19 th century, the ratio of the value in the crest part of the curve to that before or behind the part being 1.4-1.5. It seems that the climate of the Far East has a remarkable secular trend, worthy of quantitative considerations, ${ }^{(5)}$ and that the secular change of summer climate in the Far East is generally caused by the long period chnnge of the intensity and position of the North Pacific High.

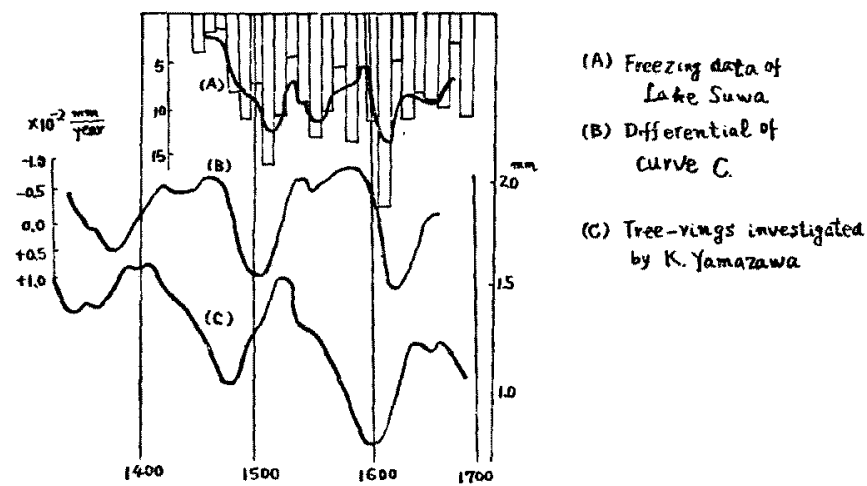

Fig. 5 Clinatic curves of the period $1300 \sim 1700$ in Japan

In Fig. 5, the climatic curves, ${ }^{(6)}$ which the author has constructed on the data of the freezing of Lake Suwa and by differentiating the curve of the growth of annual rings of trees investigated by K. Yamazawa, are shown. The similarity of the curves in Fig. 5 (A and B) and Fig. 1 ( $A$ and B) seems to suggest one of the most fundamental types of the secular change of the climate in the Far East.

\section{References and Notes}

(1) Published by the Observatory of Government-General in Korea 1917 (in Japanese).

(2) T. Taguchi: On the Diaries of the Ishikawa Family. Tenmon Sobo, Mar. 1951 No. 51 (in Japanese) .

(3) T. Yamamoto: On the Secular Change of the Climate in Japan (11). Geophysical Magar zine, Vol. 22, No. 1, p. 47.

(4) do.: do., p. $47-48$.

(5) T. Yamamoto: "Is the Climate Changing in Japan?". Kagaku 2, 1949 (in Japanese).

(6) T. Yamamoto: On the Long Period Change of Climate in the Historical Age of Japan, Kagaku, 3, 1948 (in Japanese). 